\title{
In-hospital Outcome of Patients Presenting with Acute Anterior STEMI with Complete Right Bundle Branch Block
}

\author{
Sudhakar Sarker, Abdul Wadud Chowdhury, Khandker Md. Nurus Sabah, Md. Gaffar Amin, \\ Mohammad Ali, Bishnu Pada Saha, Md. Sajjadur Rahman \\ Department of Cardiology, Dhaka Medical College Hospital, Dhaka
}

\begin{abstract}
Key words:
Ischaemic

heart disease,

Abstract

Background: Patients with acute anterior ST-segment elevation myocardial infarction (STEMI) and right bundle-branch block (RBBB) have high mortality risk, which may be stratified by early ECG changes. Our objective was to find out and to compare in-hospital outcome of patients presenting with acute anterior STEMI with or without complete RBBB.
\end{abstract} Myocardial

infarction, ECG, Right bundle branch block.

Methods: This prospective cohort study was conducted in the Department of Cardiology, Dhaka Medical College Hospital, Dhaka, over a period of one year from March 2016 to February 2017. A total of 184 patients were included in this study of which 32 patients were included in group A (acute anterior STEMI with complete RBBB) and 152 patients were included in group B (acute anterior STEMI without any BBB or fascicular block).

Results: RBBB was documented in 17.4\% (32) of patients with acute anterior STEMI. Acute LVF (50.0\% vs. $26.3 \%$, $p<0.05)$, Cardiogenic shock (31.3\% vs. $13.2 \%, p<0.05)$ and mortality $(21.9 \%$ vs $7.9 \%$, $P<0.05)$ were more frequently observed in patients with complete $R B B B$ in comparison to patients without any $B B B$ or fascicular block (FB). Among the AMI patients with $R B B B$, permanent $R B B B$ was associated with a greater incidence of acute $\operatorname{LVF}(54.2 \%$ vs $37.5 \%, p>0.05)$, cardiogenic shock $(37.5 \%$ vs $12.5 \%, p>0.05)$ and mortality ( $25 \%$ vs $12.5 \%, p>0.05)$.

Conclusion: In this study right bundle branch block accompanying acute anterior STEMI was associated with high in-hospital adverse outcomes.

(Cardiovasc. j. 2018; 11(1): 31-38)

\section{Introduction:}

Acute coronary syndrome refers to any group of symptoms attributed to obstruction of coronary arteries. ${ }^{1}$ It remains one of the leading causes of premature death in men and women despite unquestionable progress in the management and prevention of coronary artery disease. ${ }^{2}$ It accounts for 16.7 million deaths every year. ${ }^{3}$ In developing countries the prevalence of acute coronary syndrome is increasing rapidly due to increasing prevalence of risk factors of atherosclerosis, which is the major cause of acute coronary syndrome. ${ }^{4}$

The major manifestation of acute coronary artery disease is an acute ST- segment elevation myocardial infarction. ${ }^{5}$ It results from prolonged myocardial ischemia precipitated in most cases by rupture of the pre-existing plaques leading to occlusive thrombus formation in the coronary artery. ${ }^{6}$ Approximately three to four million people are estimated to suffer from acute myocardial infarction each year. ${ }^{7}$ The 2010 Heart Disease and Stroke Statistics update of the American Heart Association reported that 17.6 million persons in the United States have coronary artery disease (CAD), including 8.5 million with MI. ${ }^{8}$

The right bundle branch is a long, thin, and discrete structure composed of high-velocity conduction Purkinje fibres. It is located in the right side of the interventricular septum and occupies a subendocardial position in its superior and inferior thirds and deeper in the middle third. There are no ramifications in most of its course, but it starts to branch as it reaches the base of the anterior papillary muscle. The blood supply to the proximal segment of the right bundle is derived from the AV nodal artery, whereas the remaining two-thirds of the right bundle is supplied from the septal branches of

Address of Correspondence : Dr. Sudhakar Sarker, Department of Cardiology, Dhaka Medical College Hospital, Dhaka, Bangladesh. E-mail: sudhakar.mmc41@gmail.com 
the left anterior descending artery. 9,10 Therefore both anterior or inferior MI may be complicated by right bundle branch block (BBB) and associated high mortality. ${ }^{11}$

$\mathrm{RBBB}$ appeared to be an independent risk factor in patients with acute anterior myocardial infarction (MI). Considering the anatomy and vascular supply of the conduction system, RBBB is usually the manifestation of large anterior MI that are often accompanied by heart failure and AV block, arrhythmia. ${ }^{12}$ Furthermore, RBBB appears not only in patients with anterior myocardial infarction but is also observed frequently in acute MI of other locations, especially of the left ventricular inferior wall.

Previous studies of patients with AMI and BBB, left and right (LBBB and $\mathrm{RBBB}$ ) at hospital admission, both in prethrombolytic, ${ }^{13,14}$ and thrombolytic era ${ }^{15,16}$ have reported in general a poor overall prognosis and a high risk for shortterm death. Complete BBB, left or right, on electrocardiogram at presentation occurs in a wide range of $1 \%$ to $15 \%$ of patients with AMI and represents an independent and very important predictor of in hospital complications and poor survival for the most investigators. ${ }^{17}$ Hirulog Early Reperfusion Occlusion (HERO-2) trial showed, those who developed RBBB 60 minutes after fibrinolytic therapy was begun-and confirmed a 3- to 4fold higher 30-day mortality rate than among patients with normal intraventricular conduction. ${ }^{18}$ The high risk in these patients is often due to a large anterior wall ST-elevation AMI that also involves the interventricular septum, and the RBB conduction defect reflects ischemia or necrosis of the right bundle traversing the septum. The extent of QRS prolongation varies depending on whether or not the right-bundle conduction is completely blocked and whether other parts of the conduction system are affected. Various AV nodal or fascicular blocks may also occur with RBBB. With ST elevation MI during normal intraventricular conduction, higher ST-segment elevation is associated with larger potential infarct size and higher mortality, ${ }^{19}$ and ST resolution at 60 to 90 minutes after fibrinolytic therapy predicts better outcomes. ${ }^{20-22}$ However, little information is available in patients with RBBB.

With the advent of reperfusion therapies, resolution of bundle branch block and AV block have been reported after both primary coronary angioplasty and thrombolysis. ${ }^{23-25}$ Previous subset analysis of the Global Utilization of Streptokinase and t-PA [tissue-type plasminogen activator] for Occluded Coronary Arteries and Thrombolysis and Angioplasty in Myocardial Infarction data bases showed a relatively poorer outcome for patients with acute chest pain who subsequently developed bundle branch block than for those who maintained normal intraventricular conduction throughout the hospital period. ${ }^{26}$

\section{Methods:}

This prospective cross sectional study was conducted over a period of 1 year from March 2016 to February 2017 at the Department of Cardiology, Dhaka Medical College Hospital, Dhaka. The study complied with the Declaration of Helsinki. Prior ethical approval was obtained from the ethical review committee of $\mathrm{DMCH}$. Informed written consent was taken from each patient.

All the patients admitted in the Department of Cardiology, DMCH, with acute anterior STEMI with or without complete RBBB, who received thrombolytic therapy within the study period and fulfilled the other inclusion and exclusion criteria were taken as study sample.

Acute MI was defined as detection of a rise and/ or fall of cardiac biomarker values [preferably cardiac troponin (cTn) with at least one value above the 99th percentile upper reference limit (URL) and with at least one of the following: Symptoms of myocardial ischemia, New or presumed new significant ST-segment-T wave (ST-T) changes or new left bundle branch block (LBBB), Development of pathological Q waves in the ECG. ${ }^{27}$ STEMI was defined MI with new ST elevation at the $J$ point in at least 2 contiguous leads of $\geq 2 \mathrm{~mm}(0.2 \mathrm{mV})$ in men or $\geq 1.5 \mathrm{~mm}(0.15 \mathrm{mV})$ in women in leads V2-V3 and/ or of $\geq 1 \mathrm{~mm}(0.1 \mathrm{mV})$ in other contiguous chest leads or the limb leads. ${ }^{28}$ 
RBBB was defined as a prolonged QRS duration ${ }^{3} 120 \mathrm{~ms}$, with an $\mathrm{rsr}^{\prime}, \mathrm{rsR}^{\prime}$, or rSR' pattern in lead V1 or V2. If this was not present, the $\mathrm{R}$ wave in $\mathrm{V} 1$ had to be notched with a prolonged $\mathrm{R}$ wave peak time $>50 \mathrm{~ms}$ in V1 and normal peak time in V5 and V6. Leads V6 and I had to show a QRS complex with a wide $\mathrm{S}$ wave (S duration $>$ $\mathrm{R}$ duration or $>40 \mathrm{~ms}$ ). RBBB was further classified according to the time of appearance and disappearance. "Permanent RBBB" was when RBBB appeared after admission or was present on admission and the patient either died or was present at discharge. "transient RBBB" was when RBBB disappeared during the stay in the hospital.

Data information were collected through prepared proforma from all patients/their relatives. All patients were evaluated by detailed history, clinical examination and relevant investigation was done. 12 lead ECG at the time of admission, daily morning and as needed was taken. In-hospital outcomes- acute LVF, cardiogenic shock, arrhythmia, $2^{\text {nd }}$ and $3^{\text {rd }}$ degree AV block, post MI angina, death, were compared and analyzed.

After complied data collection from all patients, statistical analysis was performed using the statistical package for social science (SPSS) program, version 22 for Windows. Continuous parameters were expressed as mean \pm SD and categorical parameters as frequency and percentage. Comparison between groups (continuous parameters) was done by Unpaired student's t test. Categorical parameters were compared by Chi-Square test. Multivariate logistic regression analysis was performed to identify in-hospital mortality risk among patients with complete right bundle branch block. The significance of the results as determined in $95.0 \%$ confidence interval and a value of $p<0.05$ was consider to be statistically significant. The confidentiality of the patient was maintained properly when observations were compiled by the investigator.

\section{Results:}

A total of 184 patients were included in this study of which 32 patients were included in group A (acute anterior STEMI with complete RBBB) and 152 patients were included in group $B$ (acute anterior STEMI without any BBB or fascicular block).

In our study male patients were predominant and constitutes $75 \%$ in group A and $78.9 \%$ in group B. Maximum patients were in the age group 41-60 years, mean age was significantly more in group A than group $\mathrm{B}(53.91 \pm 12.21 \mathrm{vs}$ $48.43 \pm 11.15, \mathrm{p}<0.05)$. Highest percentage had the history of smoking (53.1\% vs $47.4 \%$ ) followed by HTN (50\% vs $44.7 \%)$, DL (46.9\% vs $47.4 \%$ ), Diabetes Mellitus (37.5\% vs $42.8 \%$ ) family history of CAD (15.6\% vs 16.4\%) in group A and group B respectively.

Comparison of haemodynamic profile between two groups revealed mean heart rate was $95.4 \pm 22.5$ vs $87.95 \pm 17.5$, Mean systolic blood pressure $104.4 \pm 26.9$ vs $113.4 \pm 20.4$ and mean diastolic blood pressure $63.5 \pm 12.5$ vs $68.2 \pm 10.7$ in group A than group respectively and difference was statistically significant.The mean left ventricular ejection fraction was significantly low in group A than group $\mathrm{B}(38.21 \pm 5.14$ vs $40.24 \pm 4.69$ (Table-I)

Our study revealed in-hospital mortality rate was $21.9 \%$ vs $7.9 \%$, p $<0.05$, Acute LVF $50.0 \%$ vs $26.3 \%$, $\mathrm{p}<0.05$, Cardiogenic shock $31.3 \%$ vs $13.2 \%, \mathrm{p}<0.05$ and post MI angina $53.1 \%$ vs $26.3 \%$.(Table-II)

Patients with permanent RBBB had higher incidence of in-hospital adverse outcome compared to patients with transient RBBB and revealed acute LVF (54.2\% vs $37.5 \%$ ), cardiogenic shock (37.5\% vs $12.5 \%)$ and death ( $25 \%$ vs $12.5 \%)$ respectivelyTable-III.Cardiogenic shock was the most common cause of death in both groups(Table-IV).

Pulmonary congestion demonstrated the strongest relation to in-hospital mortality $[R R=$ 2.06 (95\% CI $1.59-2.66), \mathrm{p}=0.001$ ] and complete $\mathrm{RBBB}$ was the second strongest cause of mortality among the significant variables used in this study $[\mathrm{RR}=1.77,95 \% \mathrm{CI}(1.18-2.49), \mathrm{p}$ $=0.018$.

\section{Mechanism of adverse effects of RBBB:}

With respect to short-term mortality, the prognosis of patients who developed bundle branch block depends on the underlying cause. As reported previously, the occurrence of RBBB indicates a poor prognosis in patients with 
anterior MI. ${ }^{29,30}$ The increased mortality in patients with RBBB may be due to more extensive involvement of the left ventricular wall by infarction, since pulmonary congestion was observed more frequently in patients with RBBB. An effect of the conduction disturbance on shortterm mortality may not come only from extensive left ventricular impairment. An alternative explanation for the adverse short term prognosis may be due to dys-synchrony of the ventricles.
Some have proposed that intraventricular conduction delay may further impair the ability of the failing heart to eject blood. ${ }^{31,32}$ The finding of an intraventricular conduction disturbance has been associated with clinical instability and an increased risk of death in patients with heart failure. ${ }^{32,33}$ Of several explanations proposed, sudden cardiac death due to complete AV block may be a possible explanation for the increased mortality in patients with RBBB during MI

Table-I

Demographic variables of the study population $(n=184)$.

\begin{tabular}{lccc}
\hline Variables & Group A & Group B & p value \\
\hline Age (Year) & $53.91 \pm 12.2$ & $48.43 \pm 11.15$ & $0.013^{\mathrm{s}}$ \\
Male & $75 \%$ & $78.9 \%$ & $0.622^{\mathrm{ns}}$ \\
HTN & $50 \%$ & $44.7 \%$ & $0.586^{\mathrm{ns}}$ \\
DM & $37.5 \%$ & $42,8 \%$ & $0.583^{\mathrm{ns}}$ \\
Dyslipidaemia & $46.9 \%$ & $47.4 \%$ & $0.654^{\mathrm{ns}}$ \\
Smoking & & & \\
Current smoker & $53.1 \%$ & $47.4 \%$ & \\
Ex smoker & $12.5 \%$ & $23.0 \%$ & $0.265^{\mathrm{ns}}$ \\
Non smoker & $34.4 \%$ & $29.6 \%$ & \\
family H/O IHD & $15.6 \%$ & $16.4 \%$ & 0.908 \\
Heart rate (beat min) & $95.4 \pm 22.5$ & $87.95 \pm 17.5$ & $0.039^{\mathrm{s}}$ \\
Systolic BP (mmHg) & $104.4 \pm 26.9$ & $113.4 \pm 20.4$ & $0.035^{\mathrm{s}}$ \\
Diastolic BP (mmHg) & $63.5 \pm 12.5$ & $68.2 \pm 10.7$ & $0.031^{\mathrm{s}}$ \\
Troponin- I & $31.54 \pm 11.05$ & $26.73 \pm 10.12$ & $0.017^{\mathrm{s}}$ \\
LVEF\% & $38.21 \pm 5.14$ & $40.24 \pm 4.69$ & $0.029^{\mathrm{s}}$ \\
Hospital stay (days) & $6.38 \pm 1.80$ & $5.20 \pm 1.69$ & $0.001^{\mathrm{s}}$ \\
\hline
\end{tabular}

NS $=$ Not significant $\quad S=$ Significant

Table-II

Comparison of study patients by in-hospital adverse outcome $(n=184)$.

\begin{tabular}{|c|c|c|c|c|c|}
\hline \multirow[t]{2}{*}{ Complications } & \multicolumn{2}{|c|}{ Group A $(n=32)$} & \multicolumn{2}{|c|}{ Group B $(\mathrm{n}=152)$} & \multirow[t]{2}{*}{$p$ value } \\
\hline & No. & $\%$ & No. & $\%$ & \\
\hline Death & 7 & 21.9 & 12 & 7.9 & $0.018^{\mathrm{s}}$ \\
\hline Acute LVF & 16 & 50.0 & 40 & 26.3 & $0.008^{\mathrm{s}}$ \\
\hline Cardiogenic shock & 10 & 31.3 & 20 & 13.2 & $0.011^{\mathrm{s}}$ \\
\hline Post MI angina & 17 & 53.1 & 40 & 26.3 & $0.002^{\mathrm{s}}$ \\
\hline Cardiac arrest & VT & VF & 321 & 9.46 .33 .1 & 853 \\
\hline 5.33 .32 .0 & $0.372^{\mathrm{ns}}$ & & & & \\
\hline SVT & 1 & 3.1 & 2 & 1.3 & $0.462^{\mathrm{ns}}$ \\
\hline $\mathrm{AF}$ & 3 & 9.4 & 5 & 3.3 & $0.124^{\mathrm{ns}}$ \\
\hline Complete heart block & 2 & 6.3 & 2 & 1.3 & $0.081^{\mathrm{ns}}$ \\
\hline
\end{tabular}

NS $=$ Not significant $\quad S=$ Significant 
Table-III

Comparison of study patients by in-hospital adverse outcome among $R B B B$ groups $(n=32)$.

\begin{tabular}{lccccc}
\hline Complications & \multicolumn{2}{c}{ Permanent RBBB $(\mathrm{n}=24)$} & \multicolumn{2}{c}{ Transient RBBB $(\mathrm{n}=8)$} & $\mathrm{p}$ value \\
& No. & $\%$ & No. & $\%$ & \\
\hline Death & 6 & 25.0 & 1 & 12.5 & $0.458^{\mathrm{ns}}$ \\
Acute LVF & 13 & 54.2 & 3 & 37.5 & $0.414^{\mathrm{ns}}$ \\
Cardiogenic shock & 9 & 37.5 & 1 & 12.5 & $0.186^{\mathrm{ns}}$ \\
Post MI angina & 12 & 50.0 & 5 & 62.5 & $0.539^{\mathrm{ns}}$ \\
Cardiac arrest & $\mathrm{VT}$ & $\mathrm{VF}$ & 211 & 8.34 .24 .2 & 101 \\
12.50.012.5 & $0.726^{\mathrm{ns}}$ & & & & \\
SVT & 1 & 4.2 & 0 & 0.0 & $0.557^{\mathrm{ns}}$ \\
AF & 3 & 100.0 & 0 & 0.0 & $0.293^{\mathrm{ns}}$ \\
Complete heart block & 2 & 8.3 & 0 & 0.0 & $0.399^{\mathrm{ns}}$ \\
\hline
\end{tabular}

Table-IV

Direct cause of death in study patients $(n=19)$.

\begin{tabular}{|c|c|c|c|c|c|c|}
\hline \multirow[t]{3}{*}{$\overline{\text { Variables }}$} & \multicolumn{4}{|c|}{ Group $\mathrm{A}(\mathrm{n}=7)$} & \multicolumn{2}{|c|}{ Group $\mathrm{B}(\mathrm{n}=12)$} \\
\hline & \multicolumn{2}{|c|}{$\begin{array}{l}\text { Permanent } \\
\operatorname{RBBB}(n=6)\end{array}$} & \multicolumn{2}{|c|}{$\begin{array}{c}\text { Transient } \\
\operatorname{RBBB}(\mathrm{n}=1)\end{array}$} & \multirow[b]{2}{*}{ No. } & \multirow[b]{2}{*}{$\%$} \\
\hline & No. & $\%$ & No. & $\%$ & & \\
\hline Cardiogenic shock & 3 & 50.0 & 0 & 0.0 & 6 & 50.0 \\
\hline Acute LVF & 1 & 16.7 & 0 & 0.0 & 2 & 16.7 \\
\hline Cardiac arrest & 1 & 16.7 & 1 & 100.0 & 3 & 25.0 \\
\hline $\mathrm{CHB}$ & 1 & 16.7 & 0 & 0.0 & 1 & 8.3 \\
\hline
\end{tabular}

Table-V

Relative risk of variables for in-hospital mortality in patients with acute anteriorSTEMI with complete RBBB ( $n=184)$.

\begin{tabular}{lccc}
\hline Variables & Relative risk & $95 \%$ CI & p value \\
\hline Age & 1.43 & $1.162-2.345$ & $0.025^{\mathrm{s}}$ \\
Complete RBBB & 1.77 & $1.18-2.49$ & $0.018^{\mathrm{s}}$ \\
Pulmonary congestion (acute LVF \& Cardiogenic shock) & 2.06 & $1.59-2.66$ & $0.001^{\mathrm{s}}$ \\
Troponin I & 1.52 & $1.173-2.45$ & $0.023^{\mathrm{s}}$ \\
Left ventricular EF & 1.53 & $1.125-2.46$ & $0.022^{\mathrm{s}}$ \\
\hline
\end{tabular}

\section{Discussion:}

A total of 184 patients were included in this study of which 32 patients were included in group A (acute anterior STEMI with complete RBBB) and 152 patients were included in group B (acute anterior STEMI without any BBB or fascicular block).

The overall frequency of RBBB in our study was $17.4 \%$. Islam et al. in a study from Bangladesh observed frequency of RBBB in acute MI was
$15 \%{ }^{34}$ Iwasaki et al. showed frequency of RBBB was $13.4 \%$ in patient with acute anterior MI. ${ }^{29}$

Our study showed among the RBBB group frequency of permanent RBBB $75 \%$ and transient RBBB $25 \%$. Iwasaki et al. ${ }^{29}$ showed frequency of permanent RBBB 53.6\% and transient RBBB $46.4 \%{ }^{29}$ Islam et al. observed frequency of permanent RBBB $63.65 \%$ and transient RBBB $36.37 \%{ }^{34}$ 
Male patients were predominant and constitutes $75 \%$ in group A and $78.9 \%$ in group B. Maximum patients were in the age group 41-60 years, mean age was significantly more in group $\mathrm{A}$ than group $\mathrm{B}(53.91 \pm 12.21$ vs $48.43 \pm 11.15, \mathrm{p}<0.05)$. Islam et al. observed mean age was $56 \pm 9.8$ in RBBB group and $47 \pm 12.5$ in without RBBB group. Bhali et al. ${ }^{34,35}$ in a study from Abbottabad observed mean age of 59.11 years for patients with acute MI. Khan et al. had $75 \%$ male patients in their total 340 patients in study on acute MI. ${ }^{6}$

Highest percentage had the history of smoking (53.1\% vs $47.4 \%$ ) followed by HTN (50\% vs $44.7 \%)$, DL (46.9\% vs. $47.4 \%)$, DM (37.5\% vs. $42.8 \%)$ family history of CAD (15.6\% vs. $16.4 \%)$ in group A and group B respectively and was statistically not significant $(p>0.05$ for all comparison).This findings were similar to the study done by Ali et al. and Moreno et al.

Comparison of haemodynamic profile between two groups revealed mean heart rate was significantly more in group A than group B(95.4 \pm 22.5 vs. $87.95 \pm 17.5, \mathrm{p}<0.05)$. Mean systolic blood pressure (104.4 \pm 26.9 vs. $113.4 \pm 20.4)$ and mean diastolic blood pressure $(63.5 \pm 12.5$ vs. $68.2 \pm 10.7$ ) was significantly lower in group A than group B $(p<0.05)$ and finding was consistent with Islam et $\mathrm{al}^{34}$, Bhali et al. ${ }^{35}$, Wong et al. ${ }^{18}$

The mean left ventricular ejection fraction was significantly low in group A than group B (38.21 \pm 5.14 vs $40.24 \pm 4.69, \mathrm{p}<0.05)$ and findings was similar with Islam et al. ${ }^{34}$ and Bhali et al. ${ }^{35}$

In-hospital mortality rate was almost 2.8 times greater in patients with RBBB than without any $\mathrm{BBB}$ or $\mathrm{FB}$ and was statistically significant $(21.9 \%$ vs $7.9 \%, \mathrm{p}<0.05)$, a difference similar to that found in studies done by Islam et $\mathrm{al}^{34},(27.4 \%$ vs $10.9 \%)$, Ricou et al. ${ }^{24}$ (32\% vs. $8 \%$ ).

In our study patients with RBBB group had higher incidence of in-hospital adverse outcome compared to patients without RBBB group, Acute LVF (50.0\% vs $26.3 \%$, p<0.05), cardiogenic shock $(31.3 \%$ vs. $13.2 \%, \mathrm{p}<0.05)$ and post MI angina $(53.1 \%$ vs. $26.3 \%)$ which was similar to the study done by Islam et al. ${ }^{34}$ and Iwasaki et al. ${ }^{29}$ Patients with RBBB had a relatively low incidence of second or third degree heart block overall, and complete heart block was the identified cause of death only rarely. This supports previous work showing that CHB is an uncommon cause of death without the presence of severe left ventricular dysfunction. ${ }^{11,34}$

Our study revealed patients with permanent RBBB had higher incidence of in-hospital adverse outcome compared to patients with transient RBBB and revealed acute LVF (54.2\% vs. $37.5 \%)$, cardiogenic shock (37.5\% vs. $12.5 \%)$ and death (25\% vs. $12.5 \%)$ respectively which was similar to the study done by Moreno et al. Experimental and clinical evidence suggests that transient conduction disturbances may relate to extensive but reversible ischemia and inflammatory responses surrounding the specialized conduction tissue. Rapid resolution of RBBB in MI has been described and more recently has been linked with thrombolytic therapy. Early coronary reperfusion could interrupt the advance of myocardial ischemia and salvage the conduction system from extensive dysfunction ${ }^{29,36}$

Presence of pulmonary congestion demonstrated the strongest relation to in-hospital mortality $[\mathrm{RR}=2.06(95 \% \mathrm{CI} 1.59-2.66), \mathrm{p}=0.001]$ and complete RBBB was the second strongest cause of mortality among the significant variables used in this study $[\mathrm{RR}=1.77,95 \% \mathrm{CI}(1.18-2.49), \mathrm{p}$ $=0.018$ ]. These findings were similar to the study done by Iwasaki et al. ${ }^{29}$

\section{Conclusion:}

This study showed that presence of complete RBBB in patients with acute anterior STEMI is associated with adverse in-hospital outcome in terms of death, acute LVF, cardiogenic shock, post MI angina. So, the presence of complete RBBB in patients with acute anterior STEMI should alert physicians to an increased risk of morbidity and mortality. This sub-group of patients needs early detection and more aggressive treatment and meticulous care should be taken to optimize outcome.

\section{Limitations}

Although the result of this study is statistically significant and support the hypothesis, there were some limiting factors which might affect the results. The study was conducted in a single tertiary care hospital which may not represent 
the general population. Sample size was less than desired number. All the patients with acute anterior STEMI with or without RBBB were not included due to different exclusion criteria. The study did not have the scope of long term follow up, so morbidity or complication in the long run could not be determined. It could not be confirmed whether the patients of acute anterior STEMI with complete RBBB had a new onset or old RBBB as none could show any previous ECG.

\section{Conflict of Interest - None.}

\section{References:}

1. Schoen FJ. The heart. In: Kumar V, abbas AK, Fausto N, Aster J. Eds. Robbins and Cotran pathologic basis of disease.8th Edition. Philadelphia: WB Saunders; 2010: 529587.

2. Grainger DJ, Mosedale DE. Metabolism in coronary heart disease. Heart Metab 2012; 55: 8-12.

3. Ahmed S, Ahsan MB, Ehsan Ullah. Stable angina: the frequency of coronary artery stenosis amon patients having left bundle branch block. Professional Med J 2009;16:9499 .

4. Kazim SF, Itrat A, Butt NW, Ishaq M. Comparison of cardiovascular disease patterns in two data sets of patients admitted at a Tertiary Care Public Hospital in Karachi five years apart. Pak J Med Sci 2009; 25 P55-P60.

5. Hausenloy DJ. Magnitude and relevance of reperfusion injury. Heart Metab 2012; 54: 5-8.

6. Khan S, Abrar A, Abid AR, Jan T, Khan H. In-hospital outcome of patients having acute myocardial infarction with and without streptokinase. Gomal J Med Sci 2009;7:96100.

7. Li YQ, Zhang MF, Wen H, Hu CL, Liu R, Wei HY, et al. Comparing the diagnostic values of circulating micro RNAs and cardiac troponin $\mathrm{T}$ in patients with acute myocardial infarction. Clinics (Sao Paulo) 2013; 68:75-80.

8. Lloyd-Jones D, Adams RJ, Brown TM, et al. Executive summary: heart disease and stroke statistics—2010 update: a report from the American Heart Association. Circulation 2010; $121: 948$.

9. Gann D, Balachandran PK, El-Sherif N, Samet P. Prognostic significance of chronic versus acute bundle branch block in acute myocardial infarction. Chest 1975; 67: 298-303.

10. James TN, Burch GE. Blood supply of the human intraventricular septum. Circulation 1958; 17: 391- 396.

11. Hindman MC, Wagner GS, JaRo M, Atkins JM, Scheiman MM, DeSanctis RW et al. The clinical significance of bundle branch block complicating acute myocardial infarction. II. Indications for temporary and permanent pacemaker insertion. Circulation 1978; 58: 689-699.
12. Jonis ME, Terry G, Kenmure ACF, Frequency and significance of conduction defects in acute myocardial infarction. Am heart J 1977; 94: 163-167.

13. Nimetz AA, Shubrooks SJ Jr, Hutter AM Jr, DeSanctis $\mathrm{RW}$. The significance of bundle branch block during acute myocardial infarction. Am Heart J 1975; 90: 439 -444.

14. Hollander G, Nadiminti V, Lichstein E, Greengart A, Sanders M. Bundle branch block in acute myocardial infarction. Am Heart J 1983; 105:738-743.

15. Brilakis ES, Wright RS, Kopecky SL, Reeder GS, Williams BA, Miller WL. Bundle branch block as a predictor of long -term survival after acute myocardial infarction. Am J Cardiol 2001; 88:205-209.

16. Shlipak MG, Go AS, Frederick PD, Malmgren J, Barron HV, Canto JG. Treatment and outcomes of left bundlebranch block patients with myocardial infarction who present without chest pain. J Am Coll Cardiol 2000; 36: 706-712.

17. Go AS, Barron HV, Rundle AC, Ornato JP, AvinsAL.Bundlebranch block and in hospital mortality in acute myocardial infarction. National Registry of Myocardial Infarction 2 Investigators. Ann Intern Med 1998; 129(9):690-697.

18. Wong CK, Stewart RAH, Gao W, French JK, Raffel OC, White HD; for the Hirulog and Early Reperfusion or Occlusion (HERO)-2 Trial Investigators. Prognostic differences between different types of bundle branch block during the early phase of acute myocardial infarction: insights from the Hirulog and Early Reperfusion or Occlusion (HERO)-2 trial. Eur Heart J 2006; 27: 21-28.

19. Willems JL, Willems RJ, Willems GM, Arnold AE, Van de WF, Verstraete M. Significance of initial ST segment elevation and depression for the management of thrombolytic therapy in acute myocardial infarction: European Cooperative Study Group for Recombinant Tissue-Type Plasminogen Activator. Circulation 1990; 82:1147-1158.

20. Anderson RD, White HD, Ohman EM, Wagner GS, Krucoff MW, Armstrong PW, Weaver WD, Gibler WB, Stebbins AL, Califf RM, Topol EJ. Predicting outcome after thrombolysis in acute myocardial infarction according to ST-segment resolution at 90 minutes: a substudy of the GUSTO-III trial. Am Heart J 2002; 144: 81- 88.

21. De Lemos JA, Antman EM, Giugliano RP, Morrow DA, McCabe CH, Cutler SS, et al. for the InTIME-II Investigators. Comparison of a 60 - versus 90-minute determination of ST-segment resolution after thrombolytic therapy for acute myocardial infarction. Am J Cardiol 2000; 86: 1235-1237.

22. Cura FA, Roffi M, Pasca N, Wolski KE, Lincoff AM, Topol EJ, Lauer MS. ST-segment resolution 60 minutes after combination treatment of abciximab with reteplase or reteplase alone for acute myocardial infarction (30-day mortality results from the resolution of ST-segment after reperfusion therapy substudy). Am J Cardiol 2004; 94: 859-863.

23. Hauer RN, Lie KI, Lien' KL, Durrer D. Louyterm prognosis in patients with bundle branch block complicating acute anteroseptal infarction. Am J Cardiol 1982; 49: 1581-85. 
24. Ricou F, Nicod P, Gilpin E, Henning H, Ross J. Influence of right bundle branch block on shoft and long term survival after acute anterior myocardial infarction. J Am Coll Cardiol 1991; 17: 858-863.

25. Thygesen K, Alpert JS, Talfe AS, Simoons ML, Chaitman $\mathrm{BR}$, White HD. The writing group on be half of the join ESC/ACCF/AHA/NNHF task force for the universal definition of myocardial infarction. Third universal definition of myocardial infarction. Eur Heart J 2012; 33(20): 2551-2567.

26. O'Gara PT, Kushner FG, Ascheim DD, Casey DE, Chung MK, dcLemos JA, et al. 2013 ACCF/AHA guideline for the management of ST-elevation myocardial infarction. Circulation 2013; 127: 362-425.

27. Thygesen K, Alpert JS, Jaffe AS, Simoons ML, Chaitman BR and White HD, The Writing Group on behalf of the Joint ESC/ACCF/AHA/WHF Task Force for the Universal Definition of Myocardial Infarction. Third Universal definition of myocardial infarction. Eur Heart J 2012; 33: 2551-2567.

28. O'Gara PT, Kushner FG, Ascheim DD, Casey DE, Chung MK, de Lemos JA, et al. 2013 ACCF/AHA Guideline for the Management of ST-Elevation Myocardial Infarction. Circulation 2013; 127: 362-425.

29. Iwasaki J, Kono K, Katayama Y, Takahashi N, Takeuchi K, Tanakaya M. Prognostic Significance of Right Bundle Branch Block in Patients with Acute Inferior Myocardial Infarction. Acta Med Okayama 2009; 63(1): 25-33.
30. Newby KH, Pisano E, Krucoff MW, Green C, Natale A. Incidence and clinical relevance of the occurrence of bundle branch block in patients treated with thrombolytic therapy. Circulation 1996; 94: 2424-2428.

31. Suarez G, Herrera M, Vera A, Torrado E, Ferriz J, Arboleda JA. Prediction on admission of in-hospital mortality in patients older than 70 years with acute myocardial infarction. Chest 1995; 108: 83-88.

32. Xiao HB, Brecker SJ, Gibson DG. Effects of abnormal activation on the time course of the left ventricular pressure pulse indilated cardiomyopathy. Br Heart J 1992; 68: 403407.

33. Littmann L, Symanski JD: Hemodynamic implications of leftbundle branch block. J Electrocardiol 2000; 33 : 11-121.

34. Islam MN, Ali MA, Saha GK, Islam MF, Islam KQ, Rahman MS. Incidence and Prognostic Significance of Right Bundle Branch Block Complicating Acute Myocardial Infarction. Bangladesh Med Res Counc Bull 2002; 28(no. 1): 26-35.

35. Bhalli MA, Khan MQ, Samore NA, Mehreen S. Frequency and clinical outcome in conduction defects in acute myocardial infarction. J Ayub Med Coll Abbottabad 2009; 21 (3): 32-37.

36. Linde C, Leclercq C, Rex S, Garrigue S, Lavergne T, Cazeau $\mathrm{S}$, et al. Long-term benefits of biventricular pacing in congestive heart failure: results from the Multisite Stimulation in Cardiopathy(MUSTIC) study. J Am Coll Cardiol 2002; 40: 111-118. 